Australian Journal of

Educational Technology

\title{
Distance education technologies: The fourth generation
}

\author{
James C Taylor \\ The University of Southern Queensland \\ Email: taylorj@usq.edu.au
}

\begin{abstract}
For many years distance education practitioners have enthusiastically embraced a wide range of educational technologies. In contrast, on-campus educators have tended to be satisfied with traditional approaches ignoring the new technologies of teaching and concentrating their energies on research and other scholarly activities. A review of developments in the application of a range of technologies in distance education provides an appropriate foundation for delineating the challenge to leaders and managers of conventional on-campus institutions interested in improving the quality of teaching and learning. The opportunity for institutional leaders is to adopt a proactive stance and to generate an organisational development strategy which will lead to the new technologies becoming a structurally integrated element of the teaching/learning environment.
\end{abstract}

\section{The tyranny of proximity}

In the past twenty years, there has been a significant expansion in the availability of a wide range of technologies with the potential to improve the quality of teaching and learning in higher education. Apart from the more traditional technologies such as print, broadcast television and radio, the following new technologies provide opportunities for enhancing the quality of teaching: audiotapes, videotapes, computer-based learning packages, interactive video (disk and tape), CDTV, audio-teleconferencing, audiographic communication systems (eg Smart 2000) and video conferencing. In recent times these technologies have been supplemented by the advent of the opportunities for interactivity and access to instructional resources provided by the computer communications networks popularly referred to as the "Internet" or the "Information Super Highway". By and large, distance educators have embraced these new technologies, while the application of such technologies to conventional on-campus education has been primarily piecemeal and rather limited. 
While distance educators have striven to overcome the perceived limitations associated with limited opportunities for face-to-face teaching arising from the "tyranny of distance", on-campus educators appear to be basically satisfied with conventional approaches and therefore have tended to ignore the new technologies of teaching and to concentrate their energies on research and other forms of scholarly activities. Such a state of affairs wherein teaching as a process is more-or-less taken for granted stems from the "tyranny of proximity", a frame of mind in which important issues are overlooked because they are so much an accepted part of day-to-day activities that they remain unchallenged and unquestioned (Taylor, 1994). The need to re-assess the quality of teaching in on-campus higher education is long overdue.

Probably the only defensible generalisation that one could make about the quality of teaching and learning in higher education is that being dependent on a multitude of variables including the complex interaction of the prior training, skills, motivations and idiosyncrasies of individual teachers and individual students, it is extremely variable. While some hold the view that much face-to-face teaching is both uninspired and uninspiring, others are equally adamant that it is a well-tried and tolerably effective system. Nevertheless, it seems reasonable to suggest that qualitative improvements in teaching and learning in higher education are both possible and desirable. Further, given the massive impact of technological innovation in most fields of human activity over the past 100 years, it is likely that the judicious application of new technologies to education and training could significantly improve the efficacy of the teaching-learning process in higher education. Since many distance education providers have been in the vanguard of such initiatives, a review of developments in the application of new technologies in the distance education context could be a fruitful starting point for evaluating alternative modes of delivery, which might serve to enhance the quality of teaching and learning in all higher education institutions.

\section{Distance education, face to face teaching and technology}

Although Moses is regarded by many as the first external student, it was not until print technology replaced tablets of stone as the medium of instruction that correspondence education became an accepted part of mass public education systems. The Correspondence Model, regarded generally as the first generation of distance education, has since been subsumed by the second generation Multimedia Model of distance education, which entails the use of highly-developed and refined teachinglearning resources, including printed study guides, selected readings, videotapes, audiotapes, and computer-based courseware, including computer managed learning (CML), computer assisted learning (CAL) and interactive video (disk and tape). While many institutions have evolved from using the Correspondence Model to the Multimedia Model, another 
significant trend is to move towards the third generation Telelearning Model of distance education (Nipper, 1989; Pelton, 1991; Taylor, 1992). This third generation of distance education is based on the use of information technologies, including audio teleconferencing, audiographic communication systems (eg Smart 2000), video conferencing and broadcast television/radio with attendant audio-teleconferencing. The emerging fourth generation of distance education, the Flexible Learning Model, promises to combine the benefits of high quality CD ROM based interactive multimedia (IMM), with the enhanced interactivity and access to an increasingly extensive range of teaching-learning resources offered by connection to the Internet. While distance educators continue to eagerly experiment with all four generations of technological development, oncampus education could perhaps be justifiably characterised as still leaning heavily on the first generation of technology (print). This point is not meant to devalue the potential for face to face teaching to enhance learning, but such interactivity is only one aspect of the interaction required for effective learning.

As Bates (1991) has highlighted, there are two very different types of interactivity in learning: social and individual. Social interaction between learners and teachers needs to be balanced with the individual student's interaction with teaching-learning resources, including textbooks, study guides, audiotapes, videotapes and computer assisted learning programs. He argues that the view that students in conventional institutions are engaged for the greater part of their time in meaningful, face to face interaction is a myth, and that "for both conventional and distance education students, by far the largest part of their studying is done alone, interacting with textbooks and other learning media" (Bates, 1991, p6). One of the strengths of the Multimedia Model of distance education is that it has concentrated efforts on improving the quality of the student's individual interaction with learning materials, such as specially designed printed materials, audiotapes, videotapes and computer-based learning packages, aimed at teaching concepts and cognitive skills associated with clearly defined objectives in the context of a coherent curriculum. Distance educators have also recognised the need to provide opportunities for social interaction to support effective learning and have therefore tried to simulate face to face communication through the development of instructional systems based on technologies such as audio teleconferencing, audiographic communication systems, video conferencing and computer mediated communication (CMC) that can support contiguous two-way communication between students and teachers. Alternatively, residential schools or local tutors have been used to provide for the social interaction that can facilitate effective learning. It is worth noting that the necessary balance between social and individual interactivity will vary from course to course and will be a function of such variables as the type of subject matter, the specific objectives of the course 
and the structure and quality of the learning materials, and not least the student target audience.

Because the clientele for distance education consists largely of part-time students in full-time employment, distance educators have had to provide resources (printed study guides, audiotapes, videotapes, computer-based courseware, etc) of high quality that could be used at a time and in a place convenient to each student. In effect, these "flexible access" technologies (Taylor, 1992) allow the student to turn the teacher on, or off, at will as lifestyle permits. Similarly, access to the Internet facilitates interactivity, without sacrificing the benefits of flexible access, since it can be used to support asynchronous communication. Such flexibility has a major pedagogical benefit - it allows students to progress at their own pace. Thus varying rates of individual progression can be accommodated, unlike typical conventional educational practices where the whole class tends to progress at the same pace in synchronisation with the delivery of information through mass lectures and tutorials. Some of the characteristics of the various models of distance education that are relevant to the quality of teaching and learning are summarised in Table 1.

Table 1: Models of Distance Education: A Conceptual Framework

Models of Distance Education and Associated Delivery Technologies

First Generation - The Correspondence

\section{Model}

Print
Mocond Generation - The Multimedia

Model

Audiotape

Videotape

Computer-based learning (eg

CML/CAL)

Interactive video (disk and tape)

Third Generation - The Telelearning

Model

Audio teleconferencing

Video conferencing

Audiographic Comms (eg Smart 2000)

Broadcast TV / Radio + Audio

teleconferencing

Fourth Generation - The Flexible

Learning Model

Interactive multimedia (IMM)

Computer mediated comms (CMC)

(Email, CoSy, etc)
Characteristics of Delivery Technologies Flexibility Highly Advanced

Time Place Pace Refined Interactive

Materials Delivery

Yes Yes Yes Yes No

Yes Yes Yes Yes No

Yes Yes Yes Yes No

Yes Yes Yes Yes No

Yes Yes Yes Yes Yes

Yes Yes Yes Yes Yes

No No No No $\quad$ Yes

No No No No Yes

No No No Yes Yes

No No No Yes Yes

Yes Yes Yes Yes Yes

Yes Yes Yes No Yes


While this trend towards "technology-mediated" flexible learning is perhaps inexorable in a variety of education and training contexts, it is crucial to realise that the use of a range of instructional media does not automatically enhance the quality of teaching and learning.

\section{Instructional design and technology}

It is important to note that delivery technologies (printed materials, audiotapes, videotapes, computer-based instructional systems and so on) simply package information and instruction to give students access to educational experiences. What really matters is the quality of the instructional message, rather than any inherent characteristics of the instructional medium used. The need in education to differentiate clearly between the medium and the message was highlighted by Clark (1983), who made the point that educational technologies are "mere vehicles that deliver instruction but do not influence student achievement any more than the truck that delivers our groceries causes changes in our nutrition" ( $p$ 445). It is entirely feasible to surround a teacher with a team of audiovisual technicians, graphic artists and computing specialists to vary the style of the delivery of the educational message without producing a significant increase in pedagogical efficacy.

The key process for improving the quality of teaching and learning is instructional design, which has received a significant boost from recent advances in instructional science, cognitive science and artificial intelligence, particularly expert systems (Anderson, 1982, 1985; Glaser, 1984, 1991; Kidd, 1987; Landa, 1976; Reigeluth, 1983; Winn, 1990). In the first instance, the process of instructional design entails a systematic finegrained analysis of the knowledge base and associated cognitive skills that provide the foundation of professional expertise in a particular discipline. This approach entails the application of such techniques as cognitive task analysis (Ryder \& Redding, 1993), novex analysis (Taylor, 1994), concept mapping (Novak, 1990), and knowledge engineering (Taylor \& Thomas, 1994) in order to design a sequence of well-structured learning experiences, thereby significantly enhancing the efficacy of the teachinglearning process in higher education. What appears to be required is a shift from the status quo, wherein a single teacher (often without formal professional qualifications in education) is more or less solely responsible for the design, development, delivery and evaluation of teaching programs, to a multi-disciplinary team approach, wherein a wide range of specialist expertise can be applied to the task of improving the quality of teaching and learning in higher education.

\section{Conclusion: The need for organisational development}

While the approach adopted by individual open and distance education providers is clearly a function of the specific institutional characteristics 
and unique personalities that contribute to the ethos of a particular institution, to effect qualitative change in the teaching-learning process, it is necessary to generate qualitatively different teaching-learning environments, pedagogical practices and organisational infrastructures. The opportunity for institutional leaders is to adopt a proactive stance, and to generate an organisational development strategy appropriate to the ethos of their particular institution, which will lead to the new technologies becoming a structurally integrated part of the process of teaching. Technology alone is not sufficient to foster and sustain much needed improvement in the quality of teaching and learning. If the power and sophistication of the increasing array of new technologies are to be exploited in higher education, an appropriate organisational development strategy, aimed at disseminating recent advances in instructional science and bringing about necessary restructuring, is required. Such restructuring is difficult; learning to use technology effectively is difficult; both take time; both require sustained human intervention. Therein lies the challenge to the leaders and managers of higher education institutions.

\section{Bibliography}

Anderson, J. R. (1982). Acquisition of cognitive skill. Psychological Review, 89(4), 369-406.

Anderson, J. R. (1985). Cognitive Psychology and its Implications. 2nd ed. New York: Freeman \& Co.

Bates, A. W. (1991). Interactivity as a criterion for media selection in distance education. Never Too Far, 16, 5-9.

Glaser, R. (1984). Education and thinking: The role of knowledge. American Psychologist, 37, 93-104.

Glaser, R. (1991). The maturing of the relationship between the science of learning and cognition and educational practice. Learning and Instruction, 1, 129-144.

Kidd, A. L. (1987). Knowledge Acquisition for Expert Systems. New York: Plenum Press.

Landa, L. N. (1976). Instructional Regulation and Control: Cybernetics, Algorithmization and Heuristics in Education. Englewood Cliffs, NJ: Educational Technology Publications.

Nipper, S. (1989). Third generation distance learning and computer conferencing. In R. Mason \& A. Kaye (Eds.), Mindweave: Communication, Computers and Distance Education. Oxford: Pergamon.

Novak, J. D. (1990). Concept maps and vee diagrams: Two metacognitive tools to facilitate meaningful learning. Instructional Science, 19, 29-52.

Pelton, J. N. (1991). Technology and education: Friend or foe? Research in Distance Education, 3(2), 2-9.

Reigeluth, C. M. (1983). Instructional Design Theories and Models: An Overview of Their Current Status. Hillsdale, NJ: Erlbaum. 
Ryder, J. M. \& Redding, R. E. (1993). Integrating cognitive task analysis into instructional systems development. Educational Technology Research and Development, 41(2), 74-96.

Taylor, J. C. (1992). Distance education and technology in Australia: A conceptual framework. International Council for Distance Education Bulletin, 28, 22-30.

Taylor, J. C. (1994). Novex Analysis: A cognitive science approach to instructional design. Educational Technology, 34(5), 5-13.

Taylor, J. C. (1994). Technology, distance education and the 'tyranny of proximity'. Higher Education Management, 6(2), 179-190.

Taylor, J. C. \& Thomas, N. R. (1994). A knowledge engineering approach to accounting education. Accounting Education, 3(3), 237-248.

Winn, W. (1990). Some implications of cognitive theory for instructional design. Instructional Science, 19, 53-69.

Professor James C Taylor holds the Vernon White Chair of Distance Education at The University of Southern Queensland, where he is also the Director of the Distance Education Centre. He is a member of the Commonwealth Government's Committee for the Advancement of University Teaching, and is a Vice-President of the International Council for Distance Education. His address is: Distance Education Centre, The University of Southern Queensland, Toowoomba Qld 4350, Australia. Phone: (076) 31 2279; Fax: (076) 31 2868; Email taylorj@usq.edu.au

Please cite as: Taylor, J. C. (1995). Distance education technologies: The fourth generation. Australian Journal of Educational Technology, 11(2), 1-7. http: / / www.ascilite.org.au / ajet / ajet11/taylor.html 